\title{
Recuperação e Desenvolvimento dos Municipios Brasileiros
}

$336.1: 352$

Significado e Importância da Operação Municipio

\author{
Celso Peçanha
}

\section{INTRODUÇÃO}

O Deputado Federal CELSo PeÇAnHA - recentemente eleito nas eleições de outubro passado Vice-Governador do Estado do Rio de Janeiro - é o autor do Projeto de Lei n. ${ }^{\circ}$ 3.702-58, que dispõe sôbre a instituição do Plano de Recuperação e Desenvolvimento dos Municipios Brasileiros - a Operação Municipio e dá outras providências. Dificilmente se encontratá nos Anais do Congresso Nacional um Projeto de Lei de repercusså̉o idêntica ao que foi apresentado, na presente sessão legislativa, pelo dinâmico parlamentar fluminense. Pronunciamentos autorizados dos mais eminentes economistas, engenheiros especializados em urbanismo, professôtes de direito administrativo, técnicos de administração, prefeitos, vereadores e lideres municipalistas de todo o Pais consagraram a iniciativa do Deputado Celso PeçANHA, como um empreendimento decisivo, no que se refere à emancipação global e ao desenvolvimento planificado dos Municipios brasileiros. As Prefeituras e Câmaras Municipais, em sua quase totalidade, estão articulando, sob a liderança da Associação Brasileira de Municipios, um movimento nacional de envergadara, em tôtno do Projeto n. ${ }^{\circ} 3.702-58$, tendo em vista antecipar o advento e implantação do Sistema Geral da Operação Municipio, com suas Projeções Regionais e Locais. Justifica-se, por conseguinte, a mais ampla divulgação possivel do aludido Projeto de Lei cuja aprovação, de resto, é considerada como umâ das reivindicações básicas dos Municipios brasileiros. (N. da R.) 


$$
\text { PROJETO }-\mathrm{N} .^{\circ} 3.702-1958
$$

Dispõe sôbre a Instituição do Plano de Recuperação e Desenvolvimento dos Municipios Brasileiros - Operação Municipio -.. e dá outras providências.

Art. 1. Fica instituído o Plano de Recuperação e Desenvolvimento dos Municipios Brasileiros (Operação Municipio), a ser realizado pelo Govêrno Federal em intima articulação com os governos estaduais, as prefeituras municipais e a cooperação das entidades paraestatais, autárquicas, de economia mista, não governamentais e privadas que ao mesmo aderirem.

Parágrafo único. O Plano a que o artigo se refere será precedido de acôrdo interpartidário especifico e abrangerá, primordialmente, as seguintes providências básicas: I - elaboração e execução de um programa qüinqüenal de obras, empreendimentos e serviços municipais, medida preliminar para ? desenvolvimento econômico e social dos Municipios brasileiros; II - estabelecimento, em lei especial, de um fundo financeiro de caráter permanente, com recursos federais e de outras origens, a ser administrado pelo Banco Nacional de Desenvolvimento Econômico, para auxiliar e financiar iniciativas destinadas a servirem ou beneficiarem municipios ou consórcios municipais, importando em investimentos reprodutivos a curto, médio ou a longo prazo; III - estabelecimento, em lei especial, de um sistema de descentralização administrativa dos empreendimentos e serviços federais, de maneira a instituir, permitir, promover ou facilitar a cooperação administrativa nos três niveis de govêrno; IV estabelecimento, em lei especial, de um fundo financeiro para assistência técnica, formação e aperfeiçoamento de pessoa especializada em assuntos de administração municipal ou de outros, de interêsse para o desenvolvimento econômico dos Municipios.

Art. 2. Dentro de cento e vinte (120) dias, a partir da publicação dèsta Lei, o Pnder Executivo enviará ao Congresso Nacional os projetos referidos nos itens I, II, III e IV do artigo anterior, ficando por êsse modo autorizado a constituir a Comissão Nacional Organizadora do Plano (Operação Município, Projeções Regionais e Locais), na forma do que dispõe o artigo seguinte.

Art. 3. A Comissão Nacional Organizadora do Plano será constituída de cinco (5) membros e de um (1) Diretor Executivo nomeados por decreto do Presidente da República.

Art. $4 .^{\circ}$ Fica aberto o crédito especial de $\mathrm{Cr} \$ 5.000 .000,00$ (cinco milhões de cruzeiros), pelo Ministério da Justiça e Negócios Interiores, para despesas de qualquer natureza e proveniência destinada à execução dos trabalhos atri. buídos à Comissão e seu funcionamento.

Art. $5 .^{\circ}$ Esta lei entrará em vigor na data de sua publicação, revogađas as disposições em contrário. 


\section{JUSTIFICAÇÃO}

I - PlANEJAMENTO DEMOCRÁtico E DESCENTRALIZAdo A SERVIÇO DOS MUNICÍPIOS

O Sistema Geral da "Operação Municipio e suas Projeções. Reação contra o Centralismo e a Burocracia. Estimulo à Iniciativa Privada. Um Determinismo das Condiçöes Geveconômicas do Pais. Ponto Final ao Empirismo Administrativo. Fim do Ciclo da Impro. visação.

Inadiável e da mais alta importância, a Operação Municipio com suas Projeções Regionais e Locais constitui, nesta hora, maior aspiração de tôdas as Prefeituras, Câmaras Municipais, Associações Rurais; ela é, em resumo, o "Programa-Sintese" das principais reivindicações das nossas Comunas, principalmente das populações do Interior do Pais. A Operação Municipio condensa os interêsses e esperanças de todos os Municípios brasileiros, sobretudo os da maioria absoluta que são os de orçamentos reduzidos e os desprotegidos de prestígio político. A Operação Municipio traduz, de fato, uma nova tendência de administração e govêrno em nosso País. Tendência cuja nota dominante é a reação contra os exageros do centralismo e da burocracia paralisante de velho estilo. A Operação Municipio ao mesmo tempo em que estimula os movimentos de descentralização, preconiza a implantaçâo de novos principios e métodos de planejamento, racionalização e assistência técnica; elá representa, sobretudo, um sistema geral de investimentos maciços vinculados a projetos geradores de riqueza. A Operação Municipio vem por isso mesmo dar um novo valor e conteúdo aos principios tradicionais da autonomia local, principalmente à cláusula constitucional do "peculiar interêsse". Caracteristica fundamental da Operação Municipio é o poderoso estímulo que ela proporciona à iniciativa privada. Trata-se, evidentemente, de inelutável imposição das circunstâncias politicas, geográficas, demográficas, econômicas e sociais do País, em face da própria variedade, amplitude e complexidade de problemas num território que equivale a um império continental de mais de 8,5 milhões de $\mathrm{km}_{2}$ e quase 60 milhões de habitantes - contingente demográfico que aumenta à razão de, aproximadamente, 1,5 milhões por ano. Semelhantes condições preestabelecem a conveniência de imediata e profunda reforma nos processos de funcionamento do nosso sistema federativo, o qual exige planejamento e descentralização - exatamente os traços mais caracteristicos da Operação Municipio. A Operação Municipio com suas Projeções Regionais e Locais é, acima de tudo, uma fórmula brasileira de planejamento flexivel e democrático, apoiado nos sistemas de cooperação intergovernamental e nos imperativos da descentralização administrativa. De fato, sem os métodos de um planejamento objetivo, flexivel e democrático, não poderá o Govêrno evitar os desequilibrios, desajustamento e oscilações da conjuntura, como, por outro lado, não lhe será possivel implantar as bases sólidas de uma infra-estrutura sôbre a qual possa construir o desenvolvimento progressivo das diversas unidades da Federação e o bemestar de todos os seus habitantes. Esse desenvolvimento harmonioso e equilibrado é um dos objetivos básicos da Operação Municipio. Chegou a hora de encerrar o ciclo dos esforços isolados, descontínuos e empíricos. Chegou a 
hora da Operação Municipio, isto é, um sistema profundamente democrático de planejamento e descentralização a serviço da prosperidade das Comunas e do fortalecimento do sistema federativo.

\section{II - CORREÇÃO DOS DESEQUILÍBRIOS REGIONAIS E INTEGRAÇÃO NACIONAL - PCLÍTICA DE DESENVOLVIMENTO PLANIFICADO}

\section{Uma Concepção Brasileita de Planificação Descentralizada:}

Conteúdo e peculiaridades da "Operação Municipio", Programas de Desenvolvimento Sincronizado nas Três Órbitas da Federação. Integração de Planejamentos Nacionais, Regionais e Locais. Entrosamento do Sistema Geral da "Operação Municipio" e Respectivas Projeções com os Grandes Empreendimentos Nacionais de Desen. volvimento Econômico-Social.

Coexistem, em nosso País, tipos diversos de planejamento que se deve.m articular para melhor obtenção dos alvos colimados. Daí a alternativa da fixação de diretrizes gerais e a conveniência da aplicação concentrada e sinérgica, de recursos escassos, em empreendimentos ou esquemas bem selecionados, segundo prioridades e ordens de urgência que atendam aos interêsses nacionais. Nesta obediência aos critérios de seleção, está um dos segredos do êxito da Operação Municipio, suas Projeções Regionais e Locais. Observam-se no Brasil, três tipos principais de planejamento, em condições de atender às exigências das diversas áreas a que se destinam: a) os planejamentos estruturais ou de setores econômicos, direta e primordialmente ligados ao aumento da produtividade (infra-estrutura, indústrias de base, metas preferenciais); $b$ ) os planos de aproveitamento de recursos naturais e valorização de âreas através dos esquemas de desenvolvimento regional (Valorização da Amazônia; Obras contra as Sêcas; Recuperação do Vale do São Francisco, Fłr exemplo); e c) Os Planos Locais, isto é, a planificação municipal de base. A Operação Municipio é o somatório e a articulação dêstes Planos Locais com os outros tipos fundamentais de planejamento de sentido regional e nacional. Com a Operação Municipio os Planos Locais adquirem um legitimo sentido nacional. São tipos fundamentais de planejamento que se completam e mùtuamente se fortalecem. Em todos êsses casos, os planejamentos são levados a efeito em função das condições regionais ou locais e das limitações inerentes às disponibilidades materiais, financeiras, técnicas e humanas. O conjunto das iniciativas, obras e empreendimentos ou serviços em que êsses planejamentos se concretizam, sofrem a influência de variáveis que se interrelacionam. Seria utópico pretender isolar em compartimentos estanques problemas, fôrças econômicas e realizações que, por vêzes, se entrechocam. Por outro lado, seria pueril atacar de vez todos os problemas de quase 2.500 municipalidades. Daí a seleção de áreas, a fixação de prioridades, a rigorosa escolha de projetos em função de sua indispensabilidade e rentabilidade, a concentração de recursos tendo em vista as metas ou alvos preferenciais que são os problemas de base, tais como concebidos nos esquemas da Operação Municipio em suas Projeções Regionais ou Locais. As experiências brasileiras de planejamento têm sido numerosas, o que é natural. Planos ou simples programas decorrem de necessidades concretas e não 
podem ser objeto de uma transplantação de países alienigenas. Pretende-se, com a politica do planejamento regional, acelerar o desenvolvimento das regiões retardadas, reduzir os desequilibrios interregionais, atenuar o desnivelamento dos indices de saúde, cultura e bem-estar entre as populações brasileiras, obtendo-se, pelo esfôrço coordenado, a melhoria das suas condições de vida. Essa política, no entanto, para ser objetiva deve ter sólido apoio nos Municipios ou nos Consórcios Municipais. Por êste motivo ela está reclamando a pronta execução da Operação Municipio que virá fortalecê-la em suas bases. Sem a execução preliminar da Operação Municipio, o planejamento regional corre o perigo de ser apenas uma nova modalidade de dissipação maciça de recursos, a conhecida pulverização de dotações orçamentárias sem resultados de vulto. Exatamente porque ainda não se deu início à Operação Municipio é que se generaliza a crença de que os Planos Regionais estão fracassando e as populações interessadas de grandes áreas cumeçam a sentir os desagradáveis sintomas de frustração e impaciência. Mas, a execução da Operação Municipio - com suas Projeções - é fator básico na politica de integração nacional, legítimo anseio de todos os brasileiros em têrmos de redistribuição eqüitativa das rendas, aumento da produtividade, fortalecimento do potencial humano e social do Pais. Temos, portanto, a seqüência lógica Operação Municipio, isto é, a planificação de base; os Planos Regionais, ou seja, a valorização de áreas através de politica de planejamento regional; e os Planos Setoriais - isto é, a política de fortalecimento estrutural e aparelhamento produtivo da Nação. Aspecto importante do problema é o entrosamento da Operação Municipio com os programas regionais e com os esquemas de âmbito nacional principalmente os situados nos grandes setores estruturais da economia brasileira. Nesta última categoria estão os principais empreendimentos ligados à ação do Estado na ordem econômica, as indústrias essenciais que têm de ser implantadas e que se presume devidamente sincronizadas com o desenvolvimento das pesquisas científicas e tecnológicas e o aproveitamento racional dos recursos naturais. E' tôda uma série de projetos específicos e simultâneos que devem ser coordenados: pesquisas científicas e tecnológicas, siderurgia, indústrias mecânicas e químicas de base, petróleo, refinarias, xisto betuminoso, carvão, energia atômica, sistemas elétricos, reaparelhamentos de transportes e comunicações, irrigação e conservação de solos, expansāo agropecuária, recuperação de lavouras, reflorestamento; entre tantos, êstes são problemas vitais da nacionalidade e constituem simultâneamente objetivos específicos e bases do planejamento adequado ao Brasil. A solução dêsses problemas é indispensável preliminar à politica de planejamento regional e local. Em primeiro lugar, portanto, esta Politica de Fortalecimento Estrutural.

\section{III - PROJEÇÕES REGIONAIS E LOCAIS DA OPERAÇÃO MUNICÍPIO - FORTALECI- MENTO E EXPANSÃO DAS COMUNAS BRASILEIRAS}

As Experiências Brasileiras do Planejamento. O Sistema das Projeçôes Descentralizadas da Operação Municipio. Diagnose das Dificuldades e Conjugação dos Esforços de Desenvolvimento.

No que se refere aos planos gerais, amplos e de sentido nacional, tivemos para mencionar algumas sugestivas experiências, o Plano de Obras e Equipa- 
mentos (Decreto-lei n. 6.144, de 29 de dezembro de 1943), e o Plano Salte (Lei n. ${ }^{\circ} 1.102$, de 18 de maio de 1950). Apesar de seus erros de concepção, orientação e execução, ioram úteis; muito contribuiram para acelerar o ritmo do nosso desenvolvimento. No caso especial do Plano Salte merece destaque o seu acervo de realizações que possibilitaram as Refinarias, a Frota Nacional de Petroleiros, o oleoduto Santos-Jundiai, a eletrificação de trechos ferroviários e tantas outras. Delineiam-se, aos poucos, concepções de conjunto em tôdas as regiões com os esforços do desenvolvimento da Região dos Cocais e da Carnaúba, das Obras Contra as Sêcas e Vales úmidos do Nordeste, da Bacia do Rio Paraná-Uruguai, do Vale do Rio Paraíba, da Fundação Brasil Central, dos Territórios Federais, o movimento pela interiorização e mudança da Capital e inúmeros outros. Nesse conjunto, a recuperação do Vale do Paraiba e da Baixada Fluminense apresentam real importância em virtude do abastecimento dos maiores agrupamentos demográficos do País, isto é, Rio de Janeiro, São Paulo e Sul de Minas. A essa categoria devem se acrescentar os empreendimentos de ocupação, desbravamento e colonização do Brasil Central, os núcleos agroindustriais, as emprêsas mistas que começam a surgir em quase todos os Estados. Apesar de suas reduzidas proporções financeiras, - Plano do Govêrno Federal para Financiamento de Serviços Municipais de Abastecimento de Água a partir de 1954, também é sintomático das novas tendências governamentais. Aprovado em 1953, previa a aplicação de .... Cr $\$ 800.000 .000,00$ (oitocentos milhões de cruzeiros), devemos apenas, lamentar que não tenha tido a expansão e continuidade que seria de esperar. São, portanto, as mais diversas as experiências brasileiras de empreendimentos planificados de âmbito nacional e regional; estava falatando, no entanto, apoiar êsse conjunto heterogêneo em sólidas bases e reforçá-los com a participação e apoio - direto e indireto - das Comunas Brasileiras. A Operação Municipio é o reconhecimento de que o Pais não pode continuar exclusivamente voltado para a orla atlântica ou na dependência permanente do Exterior. Ela surge em uma fase em que é bastante auspicioso verificar o progressivo crescimento do mercado interno. Cumpre assentar as bases do desenvolvimento nacional nos têrmos indicados pela geografia. Não devemos ser apenas um simples exemplo do que os econmistas costumam chamar de Economia reflexa. A Operação Municipio - com o Sistema de Projeções descentralizadas - será um passo decisivo no sentıdo de libertar o Brasil dessa humilhante situação de mero reflexo de outras economias mais desenvolvidas. Pressuposto fundamental do planejamento é o levantamento exato da situação à luz da conjuntura, o equacionamento rigoroso das condições da realidade brasileira. $\mathrm{E}$ os planejamentos que têm sido efetuados costumam ignorar essas realidades, principalmente a vida municipal, as 2.500 Comunas onde se forja, no entanto, a Renda Nacional. Todavia, de alguns anos a esta parte, êsses aspectos estão sendo objeto de cuidados. São inúmeras as investigações, estudos, projetos e relatórios já realizados, não só pelas organizações da administração pública, como inclusive por muitos técnicos estrangeiros que, a convite do govêrno, nos têm visitado. Refiro-me às Missões Taub, Cooke, Abink, Klein-Sacks e principalmente, aos estudos e projetos da Comissão Mista Brasil-Estados Unidos. Não deve ser menosprezada a importância desssa contribuição ào conhecimento das nossas condições. Os estuidos e levantamentos promovidos pelo Dr. Araújo Caval- 
CANTI - Secretário Geral da A.B.M. e que deram lugar ao aparecimento da Operação Municipio e suas Projeções Regionais ou Locais - constituem também um esfôrço extraordinário e patriótico. O esfôrço tenaz do Secretário Geral da A.B.M. está produzindo resultados da maior significação para o futuro do País; as Comunas de todo o Brasil estão despertando de sua letargia e readiquirindo a consciência de suas responsabilidades; elas já começam a se voltar sôbre si mesma efetuando levantamentos, inquéritos, sondagens, estudos diversos, preparando-se para um verdadeiro ciclo de planificação bem orientada. $\mathrm{Na}$ verdade, os problemas brasileiros já começam a ser estudados de maneira satisfatória, sendo possível obter-se, dentro em breve, a definitiva formulação dos roteiros, mais aconselháveis à ação do Estado. A experiência tem demonstrado, porém, que não se tem promovido a aplicação imediata das sugestões fornecidas. Inúmeras indicações técnicas permanecem em plano teórico, servindo, quando muito, de pura diagnose das nossas dificuldades.

Em virtude de notória deficiência de recursos, encontra-se o Govêrno - nas três órbitas da Federação - na contingência de fazer apenas o que é possivel, dentro de suas possibilidades, e não o que devera ou desejara realizar. Neste sentido, o Sistema Geral da Operação Municipio com suas Projeções descentralizadas marca o advento de uma fase de lúcida diagnose das realidades e integração dos esquemas de desenvolvimento.

IV - O` SISTEMA GERAL DA OPERAÇÃo MUNICÍPIO - PLANEJAMENTO, INVESTIMENTOS REPRODUTIVOS E DESCENTRALIZAÇXO

Aproveitamento Cientifico e Transformação das Áreas Subdesenvolvidas. Coordenação dos Planejamentos. Primado da Cooperação Intergovernamental e Interadministrativa.

A preocupação dos Governos tem sido nos grande países, quer isoladamente quer em regime de cooperação internacional, promover a recuperação das áreas subdesenvolvidas de modo a proporcionar o bem-estar de consideráveis massas hunnanas ainda não satisfatòriamente incorporadas aos benefícios da civilização. Entre essas áreas enquadram-se consideráveis porções do território brasileiro, onde os contrastes de cultura são evidentes, recapitulando os diversos estágios da evolução humana.

O Brasil não é apenas representado pelas suas capitais, de onde se têm irradiado surtos de atividades, por vêzes predatória que estenderam a obra de ocupação nacional aos limites geográficos de uma das maiores nações da Terra. O Brasil é também representado pelos imensos vazios geográficos a maior parte dos quais - representando a mais elevada percentagem de seu território - ainda desafiam a tarefa civilizadora dos pioneiros.

Em grandes extensões do território brasileiro, pequenos núcleos de baixa densidade assumem a função de pontas de lança de desbravamento e ocupação econômica. A par dêsses vazios, existem zonas imensas, onde as massas rurais ainda não se libertaram do primitivismo. Tarefas ingentes continuam a desafiar a ação do Govêrno como sejam a reorganização agrária, estabelecimento de um vasto e moderno sistema de comunicações, racionalização dos métodos 
de produção de riqueza, industrialização, elevação do poder aquisitivo dos núcleos sociais, assistência social em larga escala, sindicalização, cooperativismo, a luta contra o pauperismo das massas trabalhadoras.

Não devemos esquecer que somos uma Nação de trabalhadores pobres, preponderantemente no campo onde mourejam as massas rurais, até agora à margem dos benefícios que a legislação trabalhista já proporciona aos homens da cidade. Os nossos índices de renda per capita são dos mais baixos do mundo. Como poderemos resolver tantos problemas simultâneamente contando apenas com os nossos recursos - de vez que a participação alienígena sôbre aleatória é insignificante? E como resolvê-los sem cometer a injustiça de esquecer os Municipios e seus habitantes, os milhões de trabalhadores anônimos, o mercado interno onde se vão buscar todos os recursos, as áreas de onde tudo se tira e às quais nada se devolve? Tais fatos impõe uma politica nacional de valorização do Homem e da Terra - redistribuição de renda, produtividade e melhores condições de vida, em suma, os ideais a longo prazo, da Operação Municipio, cujos projetos selecionados envolvem êsse complexo de problemas. Problemas a serem resolvidos segundo os impositivos do planejamento e da descentralização. As realizações como a Valorização Econômica da Amazônia, as Obras Contra as Sêcas, os projetos de São Francisco, o aproveitamento hidrelétrico de Paulo Afonso, os Serviços do Vale do Rio Doce, a Fundação Brasil-Central, os planos em elaboração para aproveitamento da Bacia dos Rios Paraná-Uruguai e do Vale do Paraíba, a administração dos Territórios Federais, a interiorização da Capital Federal e outros assinalam etapas precursoras e condicionantes da Operação Municipio, a qual representa pela conjugação dos esforços dos três niveis da Federação, uma nova tendência de govêrno e administração assegurando, em seus delineamentos técnicos, o prımado da cooperação, intergovernamental e interadministrativa.

Os ideais e projetos da Operação Municipio, suas Projeções Regionais e Locais, já estão empolgando o Brasil - apesar das ameaças esporádicas de estrangulamento e colapso dos programas nacionais de desenvolvimento econômico face à crise do balanço de pagamento, os sobressaltos de uma conjuntura deficitária, a escassez de divisas e os obstáculos criados pela burocracia. Tudo indica, porém, que os obstáculos antepostos ao processo de industrialização intensiva e descentralizada de um país em plena expansão serão superados pela capacidade de iniciativa, energia \& trabalho coordenado do Congresso Nacional, do Povo e do próprio Govêrno.

O Sistema Geral da Operação Municipio é o elo que estava faltando na articulação dos diversos tipos de planejamento dos quais, aliás, participará. Essas experiências aconselham prosseguir neste roteiro; não é possivel a esta altura, recuar a fórmulas políticas e administrativas obsoletas, regredir ao regime da omissão ou da inércia em face dos problemas. Com a Operação Municipio e suas Projeções, as Comunas brasileiras participarão do grande esforço nacional conjunte, reforçandu as possibilidades de êxito dos outros planejamentos - os quais, entrosados, adquirirão o sentido de base e radicação que estava faltando. Ao mesmo tempo, por intermédio da Operação Município terão as nossas Comunas asseguradas as suas possibilidades de desenvolvimento equilibrado, organizado e progressivo. 